\title{
Progesterone does raise disgust
}

\author{
Paola Bressan (iD) and Peter Kramer (iD \\ Dipartimento di Psicologia Generale, University of Padova, Italy
}

\begin{abstract}
In the phase between ovulation and potential implantation of the egg, and especially during pregnancy, females downregulate their immune system to prevent it from attacking the (future) embryo, which is after all a half-foreign organism. Yet this adaptive mechanism, that is set off by rising progesterone, makes females more vulnerable to pathogens at those critical times. It has been proposed that, to compensate this depression of physiological immunity, progesterone reinforces behavioral immunity-by increasing proneness to disgust and hence active avoidance of infection-but evidence is inconclusive and indirect. Manipulating progesterone directly, a recent, crucial study on female mice's disgust for infected males came up empty handed. Here, reanalyzing these data in a more statistically sensitive manner, we show that progesterone not only raises disgust but does so in a way that is both significant and substantial.
\end{abstract}

\section{Keywords}

behavioral immune system, compensatory prophylaxis hypothesis, pathogens, mate choice, social avoidance, infection, disgust, progesterone, allopregnanolone

This is the accepted pre-publication version of the article:

Bressan, P., \& Kramer, P. (2021). Progesterone does raise disgust. Hormones and Behavior.

Available online 2 February 2021. doi: 10.1016/j.yhbeh.2021.104937

Even with no help from a pandemic, viruses and bacteria kill over 15 million people a year (Morens et al., 2004). Forced to cohabit with parasites from the very beginning, we animals have indeed been pushed to develop a suite of protective emotions - including, prominently, disgustand behaviors, such as avoidance of infected conspecifics (Curtis et al., 2004; Hart, 2011; Kavaliers et al., 2019). That is, we have evolved a behavioral immune system alongside our physiological one (Thornhill and Fincher, 2014; Murray and Schaller, 2016; Kramer and Bressan, in press). Yet because each system is costly to run, it would stand to reason that behavioral immunity is upregulated whenever physiological immunity is already engaged or else restrained for some specific purpose-an idea known as the compensatory prophylaxis hypothesis (Fessler, 2001; Fleischman and Fessler, 2011).

\section{Corresponding Author:}

Paola Bressan or Peter Kramer, Dipartimento di Psicologia Generale, Università di Padova, Via Venezia 8, 35131 Padova, Italy. E-mail: paola.bressan@unipd.it or peter.kramer@unipd.it 
A crucial, recurring occasion for such restraint arises every time a female's body gets ready for a possible pregnancy. The physiological immune system is then held down to prevent it from attacking the future embryo, which inevitably carries foreign genetic material that could be mistaken for a pathogen (for reviews, see Fessler, 2001; Fessler et al., 2002; Fleischman and Fessler, 2011; see also Fessler et al., 2005). During the estrous or menstrual cycle, this depression of immunity occurs between ovulation and potential implantation of the egg, and is brought about by rising levels of the sex steroid progesterone (Fessler et al., 2002). Some strands of evidence do suggest that an increment in progesterone is associated with stronger disgust, but the final word has not yet been spoken. On the one hand, among women whose physiological immune system is already fighting an infection, those in the phase that follows ovulation are more easily disgusted than those in the phase that precedes it (Milkowska et al., 2019; see also Fessler et al., 2005). Consistently, worries about contagion, and repulsion for photographs associated with it, appear to track progesterone levels in saliva (Fleischman and Fessler, 2011). On the other, a large study failed to find that pathogen disgust was affected by natural variations in progesterone (or, for that matter, any of several other steroid hormones: Jones et al., 2018). However, because disgust was measured by presenting repeatedly (typically 5-10 times) the exact same questionnaire to the exact same women, it is hard to exclude that participants, in responding to later questionnaires, were influenced by what they had responded to earlier ones-a methodological weakness that could have obscured any underlying fluctuations in disgust.

Direct manipulation of hormone levels could, of course, be a promising way to settle the issue. In humans this would run into ethical constraints, but a very recent study did it in mice (Kavaliers et al., 2021). In an exemplary display of a well-oiled behavioral immune system, estrous female mice prefer - that is, spend more time investigating — the odor of a healthy male over the odor of one that harbors a subclinical infection. Or put another way, they are "disgusted" by the infected mouse (Kavaliers et al., 2019). Here (Kavaliers et al., 2021, Experiment 1), in three experimental conditions, female mice received an injection of either allopregnanolone, a naturally produced sex steroid that is made from progesterone, or a low or high dose of progesterone itself. In two control conditions, they got a placebo injection of diluted peanut oil or were left alone. An ANOVA that tested the effect of condition (5 levels) on preference for the infected male turned out nonsignificant. The authors concluded that their results do not "support the suggestion that progesterone enhances the expression of pathogen disgust" and hence provide only "minimal support" for the compensatory prophylaxis hypothesis (Kavaliers et al., 2021, p. 5).

Considering how momentous such a conclusion is, we paid special attention to the statistics upon which it was based. ${ }^{1}$ In their analysis, the authors treated all five conditions the same, regardless of whether they were control conditions or experimental ones. It seems to us, however, that it may be more reasonable to ask not whether any single condition is different from the others but whether the hormone-treated group is different from the control group (see also Vickers, 2005). As the number of observations in these two groups is much larger than in each of the five conditions separately, a further advantage of this test is that it carries more statistical power.

\footnotetext{
${ }^{1}$ Incidentally, elsewhere in the paper, a missing zero in a $p$-value made a significant result seem nonsignificant. The authors report that females treated with a low dose of progesterone showed no preference for the odor of either a familiar or an unfamiliar male, $t(9)=-3.072, p=0.13$. In reality they preferred the familiar one, $t(9)=-3.072, p=0.013$.
} 
Using the authors' data we find indeed that, compared to those in the control group, the mice in the hormone-treated group spent significantly less time near the odor of the infected male, $F(1,48)=8.326, p=0.006, \eta_{\mathrm{p}}{ }^{2}=0.148$ (Figure 1). This effect, corresponding as it does to a more familiar Cohen's $d=0.8$, is a large one, being about the size of people's preference for their own group over other groups (Richard et al., 2003). Thus, progesterone turns out to have a significant and substantial impact on females' disgust for infected males.

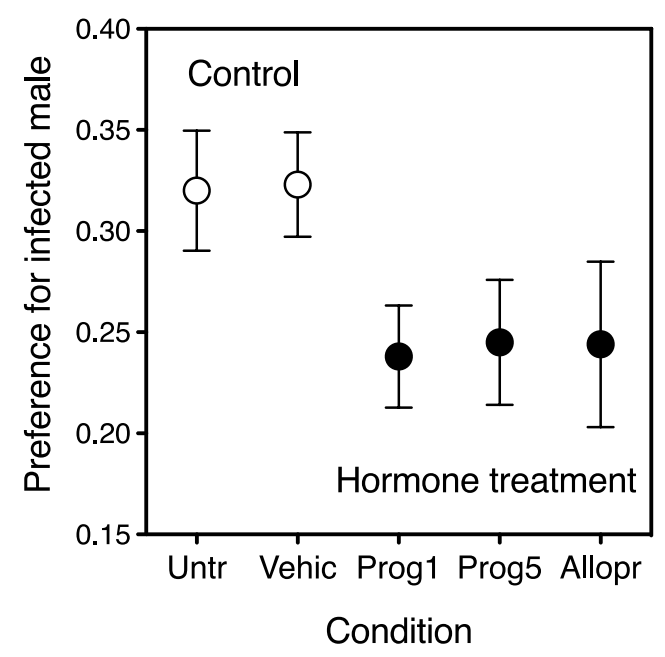

Fig. 1. Preference of estrous female mice for an infected male as a function of whether they were (solid symbols) or were not (open symbols) treated with progesterone or its metabolite allopregnanolone. Conditions: Untreated, Vehicle (diluted peanut oil), Progesterone $1 \mathrm{mg} / \mathrm{kg}$, Progesterone $5 \mathrm{mg} / \mathrm{kg}$, Allopregnanolone. Preference is expressed as the proportion of time spent near the odor of the infected vs uninfected male. Error bars indicate one standard error of the mean. All means are lower than 0.50 (random choice), showing that females are normally "disgusted" by the infected mouse; solid symbols are lower than open ones, suggesting that hormones of the progesterone family increase disgust further. The difference between Control and Hormone treatment is large $\left(d_{\text {Coben }}=0.8\right)$ and statistically significant $(p=0.006)$. Data source: Kavaliers et al. 2021, Experiment 1.

The behavioral immune system has been shown to be powerfully regulated, at least in mice, by the concerted action of the hormones oxytocin, vasopressin, estrogen, and testosterone (Choleris et al., 2012; Kavaliers and Choleris, 2018; Kavaliers et al., 2020). It would indeed be remarkable if progesterone, often mentioned in the same breath as the latter two, turned out to be a passive bystander, with no effect on infection avoidance. Thus, the data of Kavaliers et al. (2021) fill an important gap in the puzzle, and do it in a way that makes evolutionary sense. They neatly support the idea that, as females are forced to dampen down their physiological immunity, progesterone compensates by ramping up their behavioral one.

\section{Acknowledgements}

We wish to thank Martin Kavaliers for kindly and very promptly sending us the original data. 


\section{References}

Choleris, E., Clipperton-Allen, A.E., Phan, A., Valsecchi, P., Kavaliers, M., 2012. Estrogenic involvement in social learning, social recognition and pathogen avoidance. Front Neuroendocrinol 33, 140-159. https://doi.org/10.1016/i.yfrne.2012.02.001

Curtis, V., Aunger, R., Rabie, T., 2004. Evidence that disgust evolved to protect from risk of disease. Proc R Soc B 271 Suppl 4, S131-3. https://doi.org/10.1098/rsbl.2003.0144

Fessler, D.M.T., 2001. Luteal phase immunosuppression and meat eating. Riv Biol/Biol Forum 94, 403-426. https://doi.org/10.1400/22867

Fessler, D.M.T., 2002. Reproductive immunosuppression and diet: An evolutionary perspective on pregnancy sickness and meat consumption. Curr Anthropol 43, 19-61. https://doi.org/10.1086/324128

Fessler, D.M.T., Eng, S.J., Navarrete, C.D., 2005. Elevated disgust sensitivity in the first trimester of pregnancy. Hum Behav Hul 26, 344-351. https://doi.org/10.1016/j.evolhumbehav.2004.12.001

Fleischman, D.S., Fessler, D.M.T., 2011. Progesterone's effects on the psychology of disease avoidance: Support for the compensatory behavioral prophylaxis hypothesis. Horm Behav 59, 271-275. https://doi.org/10.1016/j.yhbeh.2010.11.014

Hart, B.L., 2011. Behavioural defences in animals against pathogens and parasites: Parallels with the pillars of medicine in humans. Phil Trans $\mathrm{R}$ Soc $\mathrm{B}$ 366, 3406-3417. https://doi.org/10.1098/rstb.2011.0092

Jones, B.C., Hahn, A.C., Fisher, C.I., Wang, H., Kandrik, M., Lee, A.J., Tybur, J.M., DeBruine, L.M., 2018. Hormonal correlates of pathogen disgust: Testing the compensatory prophylaxis hypothesis. Hum Behav 39, 166-169. https://doi.org/10.1016/j.evolhumbehav.2017.12.004

Kavaliers, M., Bishnoi, I.R., Ossenkopp, K.-P., Choleris, E., 2021. Differential effects of progesterone on social recognition and the avoidance of pathogen threat by female mice. Horm Behav 127, 104873. https://doi.org/10.1016/j.yhbeh.2020.104873

Kavaliers, M., Choleris, E., 2018. The role of social cognition in parasite and pathogen avoidance. Phil Trans R Soc B 373, 20170206. https://doi.org/10.1098/rstb.2017.0206

Kavaliers, M., Ossenkopp, K.-P., Choleris, E., 2019. Social neuroscience of disgust. Genes Brain Behav 18, e12508. https://doi.org/10.1111/gbb.12508

Kavaliers, M., Ossenkopp, K.-P., Choleris, E., 2020. Pathogens, odors, and disgust in rodents. Neurosci Biobehav Rev 119, 281-293. https://doi.org/10.1016/j.neubiorev.2020.09.037

Kramer, P., Bressan, P., in press. Infection threat shapes our social instincts. Behav Ecol Sociobiol.

Milkowska, K., Galbarczyk, A., Jasienska, G., 2019. Disgust sensitivity in relation to menstrual cycle phase in women with and without an infection. Am J Hum Biol 31, e23233. https://doi.org/10.1002/ajhb.23233

Morens, D.M., Folkers, G.K., Fauci, A.S., 2004. The challenge of emerging and re-emerging infectious diseases. Nature 430, 242-249. https://doi.org/10.1038/nature02759

Murray, D.R., Schaller, M., 2016. The behavioral immune system: Implications for social cognition, social interaction, and social influence, in: Olson, J.M., Zanna, M.P., (Eds.), Advances in Experimental Social Psychology, Volume 53, Elsevier Academic Press, Cambridge, pp. 75-129.

Richard, F.D., Bond Jr., C.F., Stokes-Zoota, J.J., 2003. One hundred years of social psychology quantitatively described. Rev Gen Psychol 7, 331-363. https://doi.org/10.1037/10892680.7.4.331 
Thornhill, R., Fincher, C.L., 2014. The Parasite-Stress Theory of Values and Sociality. Springer, New York.

Vickers, A.J., 2005. Analysis of variance is easily misapplied in the analysis of randomized trials: A critique and discussion of alternative statistical approaches. Psychosom Med 67, 652-655. https://doi.org/10.1097/01.psy.0000172624.52957.a8 